\title{
ENSAIOS COMPARATIVOS DE CULTIVARES DE TRIGO EM DIFERENTES REGIÕES PAULISTAS NO BIÊNIO 1979/80 (1)
}

\author{
JOÄO CARLOS FELfCIO $\left({ }^{2,5}\right)$, \\ ANTONIO WILSON PENTEADO FERREIRA FILHO (2), \\ JAIRO LOPES DE CASTRO $\left({ }^{3,5}\right)$ e BENEDITO DE CAMARGO BARROS $\left({ }^{4}\right)$
}

\section{RESUMO}

Visando estudar o comportamento de cultivares de trigo recomendados para solos com ou sem alumínio nocivo na camada arável, juntamente com outros cultivares comerciais, foram rcalizados vários ensaios nas regiōes tritícolas paulistas no biênio 1979/80. Nos experimentos em solos com alumínio, somente 'IAC-21' e 'BR-4' apresentaram produçōes médias superiores à testemunha ' $\mathrm{BH}-1146$ ', enquanto nos solos sem alumínio os cultivares Tucano, Anahuac, El Pato, Mitacore, Aracatu, Sema 220, MR 74042 e MR 74501 alcançaram as melhores médias de produção. Entre os cultivares comerciais testados, IAC-13, INIA-66, Itapua-5, PAT-24, IAC-17, IAC-5, BH-1146 e Tobari-66 revelaram as melhores produçōes, variando de acordo com a região. De maneira geral, em condições de campo, os cultivares PAT-24, IAC-13, INIA-66, CNT-8, Alondra, MR-74044, MR 74501 e Sparrow "S" apresentaram os menores índices de infecção de Puccinia graminis f. sp. triti$c i$. Com relação à ferrugem da folha $(P$. recondita), os cultivares IAPAR-1 (Mitacore), IAPAR-3 (Aracatu), Alondra e CNT-8 tiveram os mais baixos índices de infecção.

Termos de indexação: Triticum aestivum L., produçăo, alumínio tơxico, resistência, Puccinia graminis f. sp. tritici, Puccinia recondita.

(l) Recebido para publicação em 2 de agosto de 1983. nas (SP).

(2) Seção de Arroz e Cereais de Inverno, Instituto Agronômico (IAC), Caixa Postal 28, 13001 Campi-

(3) Estação Experimental de Capão Bonito, IAC.

(4) Seçăo de Doenças das Plantas Alimentrcias Básicas e Olerfcolas, Instituto Biológico.

(5) Com bolsa de suplementação do CNPq. 


\section{INTRODUÇĀO}

A cultura do trigo foi introduzida no Estado de São Paulo a partir de 1535, chegando a uma relativa situação de crescimento em certo período da ęra colonial (BAYMA, 1960). Nos dias atuais, São Paulo é o terceiro produtor nacional, com sua área cultivada representando 4,5\% na safra agrícola de 1979 (BANCO DO BRASIL..., 1979).

Segundo DUARTE (1974), as condições de clima e solo das regiões onde se produz tradicionalmente o trigo no Brasil, são bastante negligenciadas nas análises dos problemas da triticultura nacional.

Conforme BAYMA (1960), o Bandeirante foi o primeiro cultivar de trigo semeado com sucesso, em março de 1947, na região de Itapetininga, com rendimentos que variaram de 1.050 a $2.400 \mathrm{~kg} / \mathrm{ha}$.

$\mathrm{O}$ deslocamento da tradicional área de trigo paulista para o Vale do Paranapanema, uma regiăo ecologicamente melhor para a cultura, deveu-se principalmente às condições de maior fertilidade dos solos (DUARTE, 1974).

Uma resistência estável a três espécies de Puccinia sp. (Puccinia graminis f. sp. tritici, $P$. recondita e $P$. striformis), causadoras das ferrugens, continua sendo o principal objetivo dos programas de melhoramento do trigo no CIMMYT (INFORME..., 1979). Por muitos anos, as ferrugens têm constituído fator limitante ao cultivo do cereal. Recombinaçōes dos genes para patogenicidade representam sempre novas ameaças para os cultivares de trigo, sobretudo para aqueles previamente considerados resistentes às raças prevalecentes.

Foram analisadas, em 1978, amostras de ferrugem do colmo colhidas no Estado de São Paulo, e identificadas as raças $11,11 / 74,11 / 78,15 / 65,15 / 78$, 17 e 17/61. Nas amostras colhidas e analisadas em 1979, foi identificada inclusive a raça $17 / 63$ (COELHO, 1980).

De acordo com FELICIO (1980), os cultivares IAC-5 (Maringá), BH-1146 Tobari-F-66, La-1434 e IAC-17 (Maracai) foram considerados preferenciais para a semeadura no Vale do Paranapanema, e apenas o 'IAC-5' para a região Sul do Estado de São Paulo.

Este trabalho visou determinar o comportamento de cultivares de trigo em duas regiōes triticolas paulistas no biênio 1979/80.

\section{MATERIAL E MÉTODOS}

Os cultivares foram divididos em grupos quanto à tolerância à acidez do solo (MUZZILLI et alii, 1978): cultivares de trigo para solos sem $\mathrm{Al}^{3+}$ (denominados suscetíveis); cultivares para solos com $\mathrm{Al}^{3+}$ (denominados 
tolerantes) e cultivares comerciais. Foram os seguintes os cultivares que compuseram os diversos ensaios:

\section{Ensaios de cultivares de trigo para solos sem alumínio nocivo}

1. Em 1979, tais ensaios foram constituídos dos seguintes cultivares: Anahuac, BH-1146, El Pato, IAC-5, IAC-15, IAPAR-1 (Mitacoré), IAPAR-3 (Aracatu), MR-74042, MR-74044, MR-74501, Nambu, Paraguai-281, Sema 220, Sparrow "S", Alondra-45, Alondra-46, Hork, IA 781, MR 74503, Tucano e Moncho BSB, sendo considerado como testemunha o ' $\mathrm{BH}-1146$ ', tolerante ao $\mathrm{Al}^{3+}$.

2. Os ensaios de 1980 tiveram acrescidos os tratamentos: Cocoraque Diamante Inta, E 75168, IRN-583-75, Ld-7829, Ld-7835, Leones Inta MS 78-2, OC-731070, Tezopaco e Alondra 4546 (composto da mistura do Alondra-45 e 46), eliminando-se 'Hork', 'IA 781' e 'MR 74503'.

\section{Ensaios de cultivares de trigo para solos com alumínio nocivo}

1. Em 1979, tais ensaios foram compostos dos seguintes cultivares: Alondra-46, Alondra-45, BH-1146, CNT-1, CNT-9, IAC-5, IAC-18, IAC-21, IAC-H-789, PF 72640, Trigo BR-1, Trigo BR-2, Trigo BR-4 e PAT-7219, sendo considerada testemunha o ' $\mathrm{BH}-1146$ '.

2. Os ensaios de 1980 foram acrescidos dos cultivares: BR-5, Charrua, Alondra-4546 (composto), CEP-74162, CEP-7596, IA 784, IAPAR-3, Mascarenhas, OC-731129, PAT-7219, PAT-72247, PAT-73322, PAT-74116, R-30-467-77 e Tifton, sendo eliminado o 'IAC-H-789'.

\section{Ensaios de cultivares de trigo comercial}

1. Em 1979 os ensaios foram compostos dos seguintes cultivares: BH-1146, CNT-1, CNT-7, CNT-8, Confiança, IAC-5, IAC-13, IAC-17, INIA-66, Itapua-5, Jupateco-73, LA-1549, Paraguai-281, PAT-24, PAT-7219, Tobari-66, CNT-6, LA-1434, Palotina e Pampa. As testemunhas para comparação de produtividade $e$ resistência às moléstias foram ' $\mathrm{BH}-1146$ ' para o Vale do Paranapanema, em função de ser o mais cultivado, e 'IAC-5' para a região sul do Estado de São Paulo.

2. Os ensaios de 1980 foram acrescidos dos cultivares CNT-9, IAC-18, Moncho BSB, Nambu, Trigo BR-1 e Trigo BR-2, eliminando-se os cultivares CNT6. LA-1434, Palotina e Pampa.

Os ensaios foram instalados visando cobrir duas regiōes tritícolas paulistas: a do Vale do Paranapanema, com predominância de solos de boa fertilidade, e a região Sul, onde predominam solos de baixa fertilidade. Ambos os locais foram semeados durante a segunda quinzena de abril. 
No biênio 1979/80, os ensaios para solos sem alumínio tóxico foram semeados nas seguintes localidades: Fazenda Canadá, no município de Assis; Fazenda São José, no de Xavantes; Fazendas Santa inês (I) e Emilândia (II), no de Maracai, e Fazenda São Donato, no de Cruzália, todas no Vale do Paranapanema. Os ensaios para solos com $\mathrm{Al}^{3+}$, além das Fazendas São Donato e Santa Inês, foram instalados também na regiāo Sul: Estação Experimental de Capão Bonito e Cooperativa Holambra II, no municipio de Paranapanema, e Fazenda Vitória, no município de Itapeva. Os ensaios de cultivares de trigo comerciais, semeados nas mesmas localidades dos anteriores, eram constituídos de cultivares tolerantes e suscetiveis ao $\mathrm{Al}^{3+}\left({ }^{6}\right)$.

Os ensaios foram delineados em blocos ao acaso com quatro repetições, sendo cada parcela composta por cinco linhas de $5 \mathrm{~m}$ de comprimento, espaçadas de $0,20 \mathrm{~m}$, com um espaçamento lateral entre elas de $0,60 \mathrm{~m}$. A semeadura foi efetuada na base de 80 sementes viáveis por metro de sulco.

$\mathrm{Na}$ colheita, foram tomadas as cinco linhas de cada parcela, portanto, uma área útil de $5 \mathrm{~m}^{2}$. Os dados de produçăo foram submetidos à análise de variância e, para comparação das médias, empregou-se o teste de Duncan a $5 \%$ de probabilidade (GOMES, 1963).

Retiraram-se amostras compostas dos solos nos locais estudados e, de acordo com os resultados analíticos mostrados no quadro 1 , efetuou-se a seguinte adubação: sulfato de amônio com $20 \%$ de N, superfosfato simples com $20 \%$ de $\mathrm{P}_{2} \mathrm{O}_{5}$ e cloreto de potássio corn $60 \%$ de $\mathrm{K}_{2} \mathrm{O}$, os quais foram aplicados a lanço antes da semeadura e posteriormente incorporados ao solo. As quantidades de fertilizantes aplicadas nas diferentes localidades basearam-se nas tabelas de adubação e calagem do lnstituto Agronômico (CAMPINAS, 1977).

Para avaliar o comportamento dos cultivares com relação às principais doenças em condiçōes naturais de intecção, foram empregadas escalas de leitura, em condições de campo. Para a ferrugem-do-colmo (Puccinia graminis Pers. forma sp. tritici Eriks et Henn.) e ferrugem-da-folha (Puccinia recondita Rob. ex. Desm. forma sp. tritici Eriks), foram feitas avaliaçōes nas plantas após o florescimento usando a escala modificada de Cobb, conforme SCHRAM et alii (1974). Essa escala é composta por um número, estimando o percentual de ataque da moléstia no colmo e na folha, acrescido de uma letra simbolizando o tipo de reação: $S$ = suscetível (uredossoro grande coalescente sem necrose e sem clorose); MS = moderadamente suscetivel (uredossoro médio); $M=$ intermediário (diversos tipos de reaçōes); $M R=$ moderadamente resistente (uredossoro pequeno); $\mathrm{R}=$ resistente (uredossoro minúsculo rodeado de áreas necróticas).

Outras doenças, como o complexo septoriose mais helmintosporiose (Septoria sp. e Helminthosporium sp.) nas folhas, também foram avaliadas em por-

(6) Os experimentos relatados compóem partc da programaçăo da Comissāo Norte-Brasileira de Pesquisa de Trigo, responsável pela experimentação com trigo acima do paralelo $24^{\circ}$ Sul. 


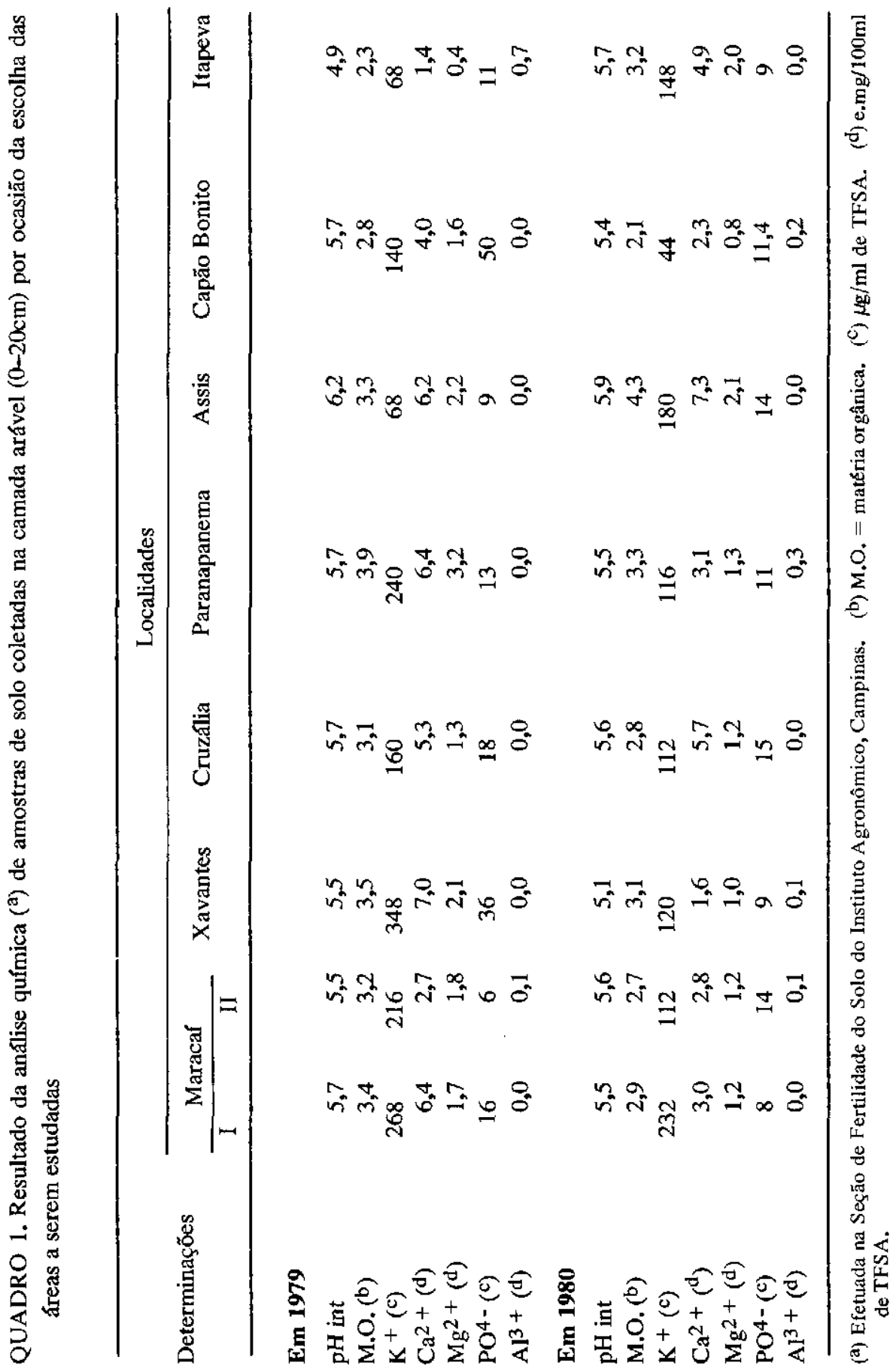


cèntagem de área foliar infectada, observando-se as quatro folhas superiores das plantas.

Também foram avaliadas a altura das plantas e o acamamento, da seguinte forma: a altura das plantas de cada cultivar foi medida no campo, levando em consideração a distância do nível do solo ao ápice da espiga, mantendo-se as plantas esticadas; para avaliação do acamamento, foram computadas notas de 0 a 5 por julgamento visual no campo, onde 0 representava ótima resistência e 5 , suscetibilidade completa, isto é, $100 \%$ das plantas acamadas.

$\mathrm{Na}$ determinação do ciclo dos cultivares estudados, segundo o número de dias da emergência da planta até sua maturação completa, considerou-se como ciclo precoce a maturação até 120 dias; ciclo médio, de 121 a 135 dias, e tardio, de 136 dias ou mais.

\section{RESULTADOS E DISCUSSÃO}

A germinação nas diferentes parcelas dos experimentos foi muito boa, assegurando bom "stand" inicial para a cultura; entretanto, os periodos de estiagem, que ocorreram de maio a junho, afetaram, em parte, o comportamento da experimentaçăo: em 1979 tais efeitos foram menores que em 1980. A grande maioria dos solos estudados apresenta baixa concentração de $\mathrm{Al}^{3+}$ na camada arável (Quadro 1) em vista das correções efetuadas pelos agricultores; todavia, essa correção é apenas superficial, o que não impede os riscos a que a cultura está sujeita, principalmente quando da ocorrência de estiagens.

Quanto à resistência às raças de $P$. graminis tritici e $P$. recondita, obsenou-se alguma diferenciação entre os cultivares, enquanto, para as manchas foliares, não se detectaram maiores diferenças nas avaliações de campo.

\section{Ensaio de cultivares de trigo para solos sem alumínio nocivo}

As observações agronômicas e fitopatológicas e a produção média de grăos dos ensaios estudados no Vale do Paranapanema, encontram-se no quadro 2. A análise conjunta dos experimentos de 1979 e 1980 , que se acha no quadro 3 , apresenta os valores de 1,38 e 1,14 para $F$, valores esses não significativos para os tratamentos estudados. Os cultivares Tucano, SEMA-220, IAPAR-1, Anahuac, MR-74501, EI Pato, IAPAR-3 e MR-74042, apresentaram maior produção de qrãos em comparação à testemunha, $\mathrm{BH}-1146$, na média do biênio.

Para a resistência às raças prevalentes de ferrugem-do-colmo ( $P$. graminis f. sp. tritici), destacaram-se os cultivares Sparrow "S", MR-74501, MR-74042, MR-74044 e os cultivares da série Alondra e IRN-583-75. Quanto à resistência às raças dominantes de ferrugem-da-folha, os cultivares IAPAR-1, IAPAR-3 e os Alondra apresentaram os menores Indices de infecção. 


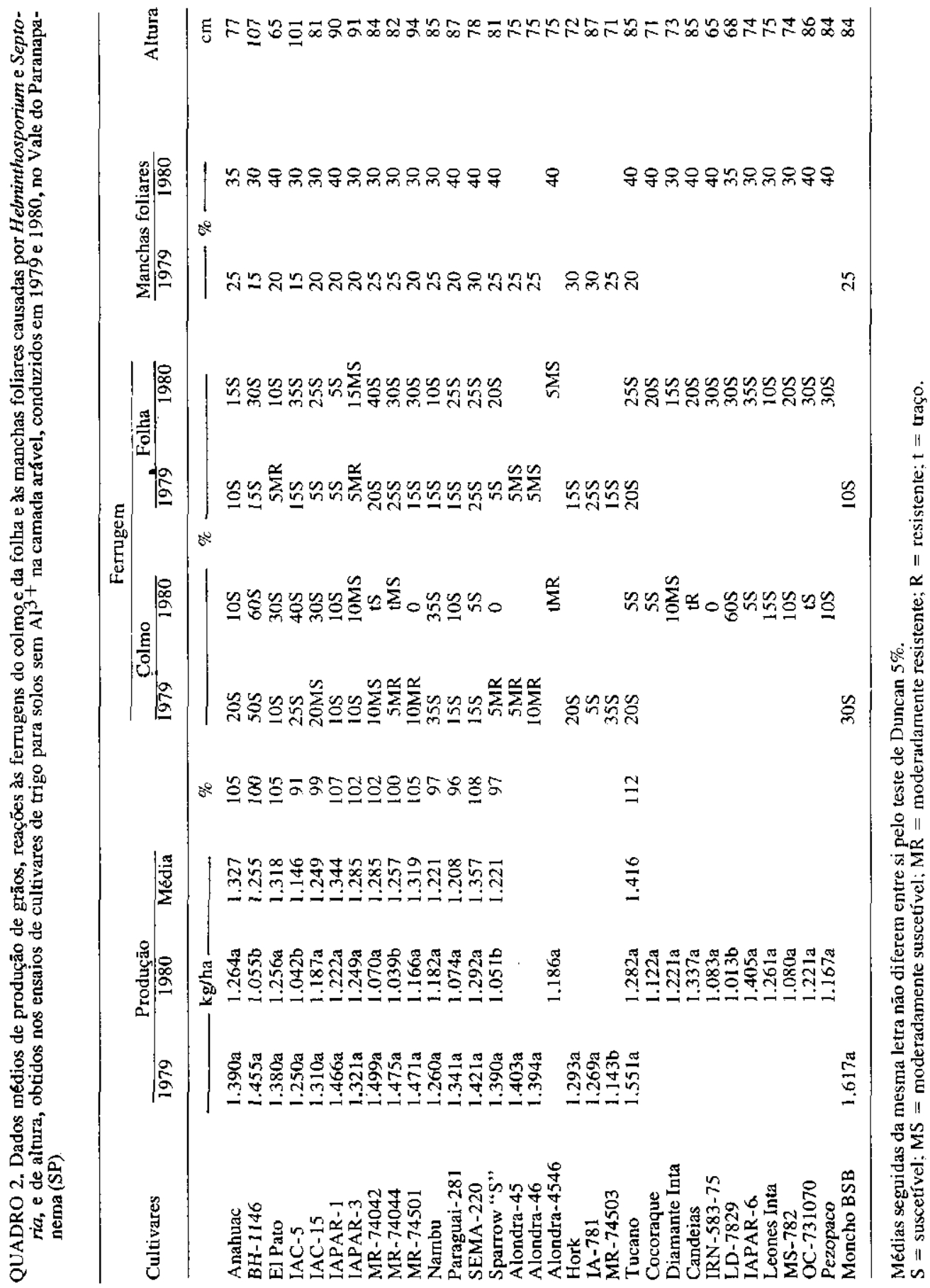


QUADRO 3. Análise da variância conjunta, por grupos de experimentos e regiōes, para a produção de grãos em kg/ha (1979/80)

\begin{tabular}{|c|c|c|c|c|}
\hline \multirow{3}{*}{ Causas de variação } & \multicolumn{4}{|c|}{ Q.M. } \\
\hline & \multicolumn{2}{|c|}{ Cultivares para solo com $\mathrm{Al}^{3+}$} & \multicolumn{2}{|c|}{ Cultivares para solo sem $\mathrm{Al}^{3+}$} \\
\hline & 1979 & 1980 & 1979 & 1980 \\
\hline Cultivar & 295868 NS & $218403 \mathrm{NS}$ & $975872 \mathrm{NS}$ & $814099(* *)$ \\
\hline Local & $30498130(* *)$ & $23587692(* *)$ & $8773452(* *)$ & 35141165 (***) $^{* *}$ \\
\hline \multirow[t]{4}{*}{ Cultivar x local } & $214023(* *)$ & $192340(*)$ & $801453(* *)$ & $323188(* *)$ \\
\hline & \multicolumn{4}{|c|}{ Cultivares comerciais } \\
\hline & \multicolumn{2}{|c|}{ Vale do Paranapanema } & \multicolumn{2}{|c|}{ Regiāo Sul } \\
\hline & 1979 & 1980 & 1979 & 1980 \\
\hline Cultivar & $585286\left(^{*}\right)$ & $320344(* *)$ & $3865726(* *)$ & $498495 \mathrm{NS}$ \\
\hline Local & $2964803(* *)$ & $8659782(* *)$ & $1272705 \mathrm{NS}$ & $15057900(* *)$ \\
\hline Cultivar $\mathrm{x}$ local & $217274(*)$ & $85007\left(^{* *}\right)$ & $658545(* *)$ & $350129\left(^{*}\right)$ \\
\hline
\end{tabular}

$(*)=$ Efeitos significativos ao nível de $5 \%$ pelo teste $\mathrm{F}$.

$(* *)=$ Efeitos significativos ao nível de $1 \%$ pelo teste $\mathrm{F}$.

NS $=$ Não-significativo.

\section{Ensaio de cultivares de trigo para solos com alumínio nocivo}

As observações agronômicas, fitopatológicas e a produção média de grãos dos ensaios estudados . no Vale do Paranapanema, conjuntamente com aqueles da regiāo Sul, encontram-se no quadro 4.

A análise da variância (Quadro 3) dos experimentos estudados em 1979 não apresentou resultado significativo; entretanto, em 1980, ocorreram diferenças significativas: os cultivares Trigo BR-5, PAT-72247, IAPAR-3, apresentaram meIhores rendimentos de grãos que os demais.

Para a produtividade de grãos no biênio, destacaram-se os cultivares de trigo BR-4 e IAC-21 (Iguassu) com produções de 5\% e $2 \%$ acima da testemunha; destacaram-se, ainda, os cultivares IAC-18, Alondra-45 e 46, em 1979, e Trigo BR-5, PAT-72247, IAPAR-3, Charrua, Alondra-4546 (composto) e CEP-7596, em 1980. 


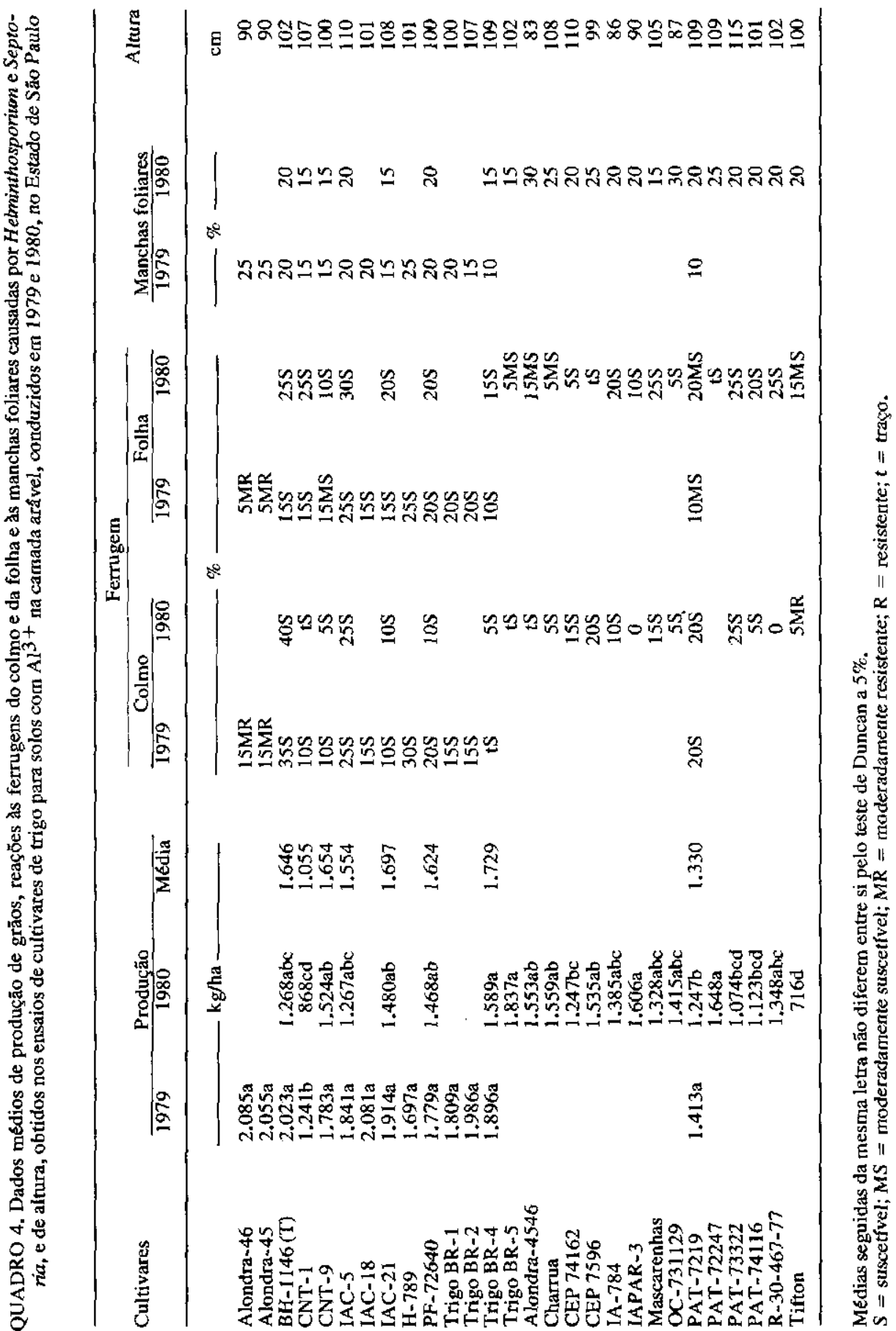


Considerando a resistência à ferrugem-do-colmo em condições de campo, destaca-se no biênio o 'BR-4' e também os cultivares Trigo BR-5, IAPAR-3, R-30-467-77, Tifton e Alondra-4546, com moderada resistência às raças do patógeno ocorrentes. Para a ferrugem-da-folha, somente os cultivares da série Alondra, PAT-72247 e CEP-7596 apresentaram algum destaque, embora se deva considerar a baixa ocorrência da doença nos dois anos.

\section{Ensaio de cultivares de trigo comercial}

As observações agronômicas, fitopatológicas e a produtividade média de grãos dos ensaios estudados no Vale do Paranapanema e na regiāo Sul encontram-se, respectivamente, nos quadros 5 e 6 .

Pelo quadro 3, verifica-se que para os ensaios do Vale do Paranapanema, os cultivares apresentam efeito significativo para a produção de grãos em 1979 , e altamente significativo em 1980, sendo também significativo o efeito local e a interação cultivar $x$ local.

Os cultivares IAC-13, INIA-66, Itapua-5, PAT-24, IAC-17 e IAC-5 apresentaram produtividade média superior ao $\mathrm{BH}-1146$, considerado como testemunha, para a região do Vale do Paranapanema. Destacaram-se em 1979, pelo teste de Duncan a 5\%, os cultivares INIA-66, CNT-6 e CNT-7, e em 1980, IAC-18, Nambu, Trigo BR-2, Itapua-5 e CNT-9.

Com relação às reações às raças de Puccinia graminis f. sp. tritici, apresentaram resistência os seguintes cultivares: $\mid A C-13$, CNT-8, PAT-24, Itapua-5 e Pampa, e com relaçäo a $P$. recondita, pode-se destacar apenas os cultivares CNT8 e PAT-7219, com reações moderadamente suscetíveis.

No Sul do Estado de Sāo Paulo, a cultura de trigo vem apresentando grande variação de produtividade, por ser normalmente semeada em abril, coincidindo o seu florescimento com a época dos maiores picos de geadas na região. $\mathrm{O}$ fator geada tem sido básico na queda da produção, principalmente pelo encarquilhamento dos grãos, acarretando baixo índice de peso hectolítrico.

A análise conjunta dos ensaios na região Sul do Estado de São Paulo (Quadro 3), evidencia em 1979 efeito de cultivares altamente significativo, e não significativo em 1980. A interação local $x$ cultivares foi evidenciada para o biênio e o efeito do local foi altamente significativo, em 1980.

Nos ensaios conduzidos na região Sul (Quadro 6), destaca-se 0 'BH-1146'; entretanto, é inconveniente sua semeadura pela alta suscetibilidade à ferrugem-do-colmo (COELHO, 1980); os cultivares IAC-13, Itapua-5, Tobari-66 e INIA-66, apresentaram produtividade média no biênio superior à da testemunha (cultivar IAC-5) para a região, enquanto os cultivares IAC-17, CNT-7, Jupateco-73 apresentaram, estatisticamente, o mesmo valor que a testemunha. 


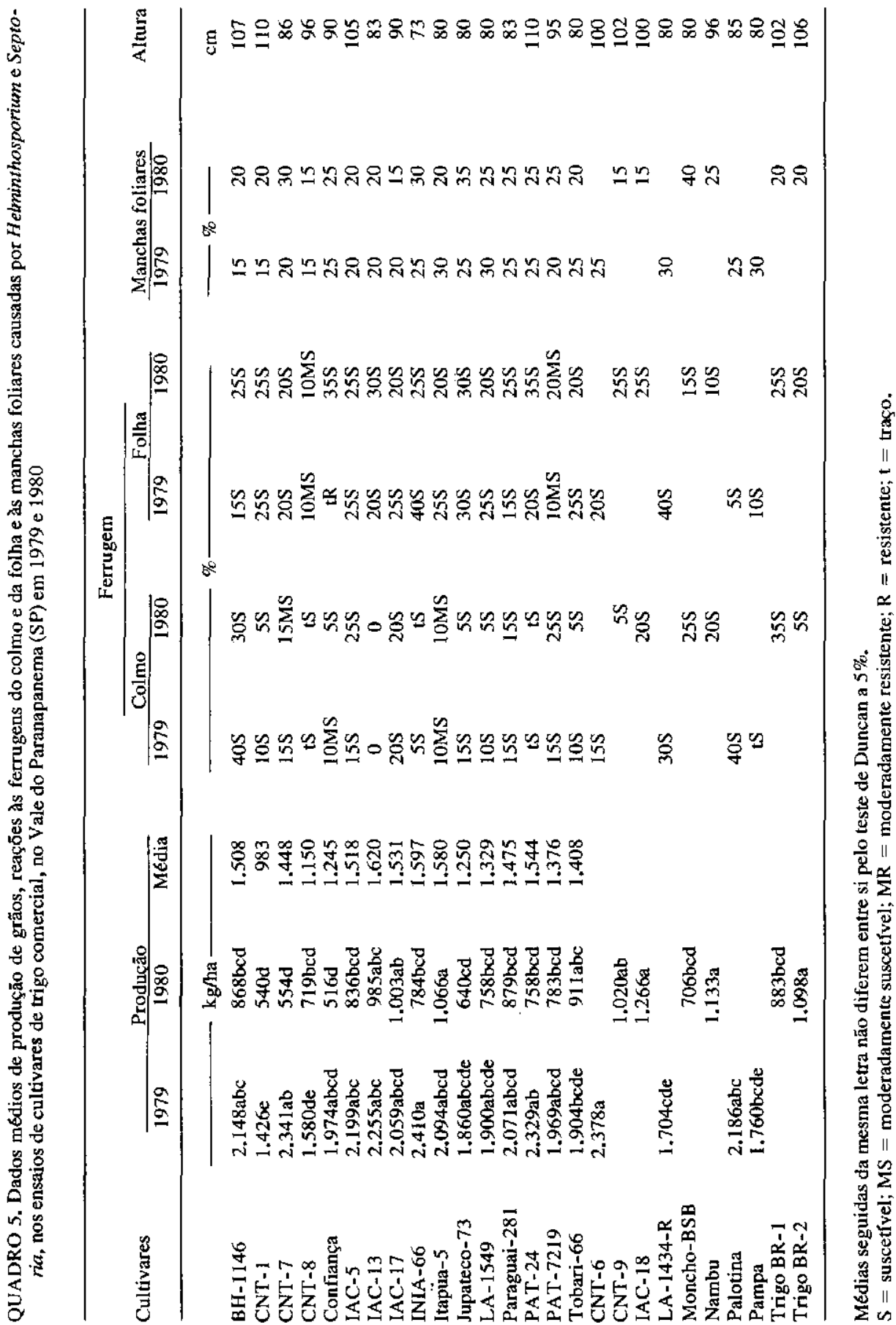




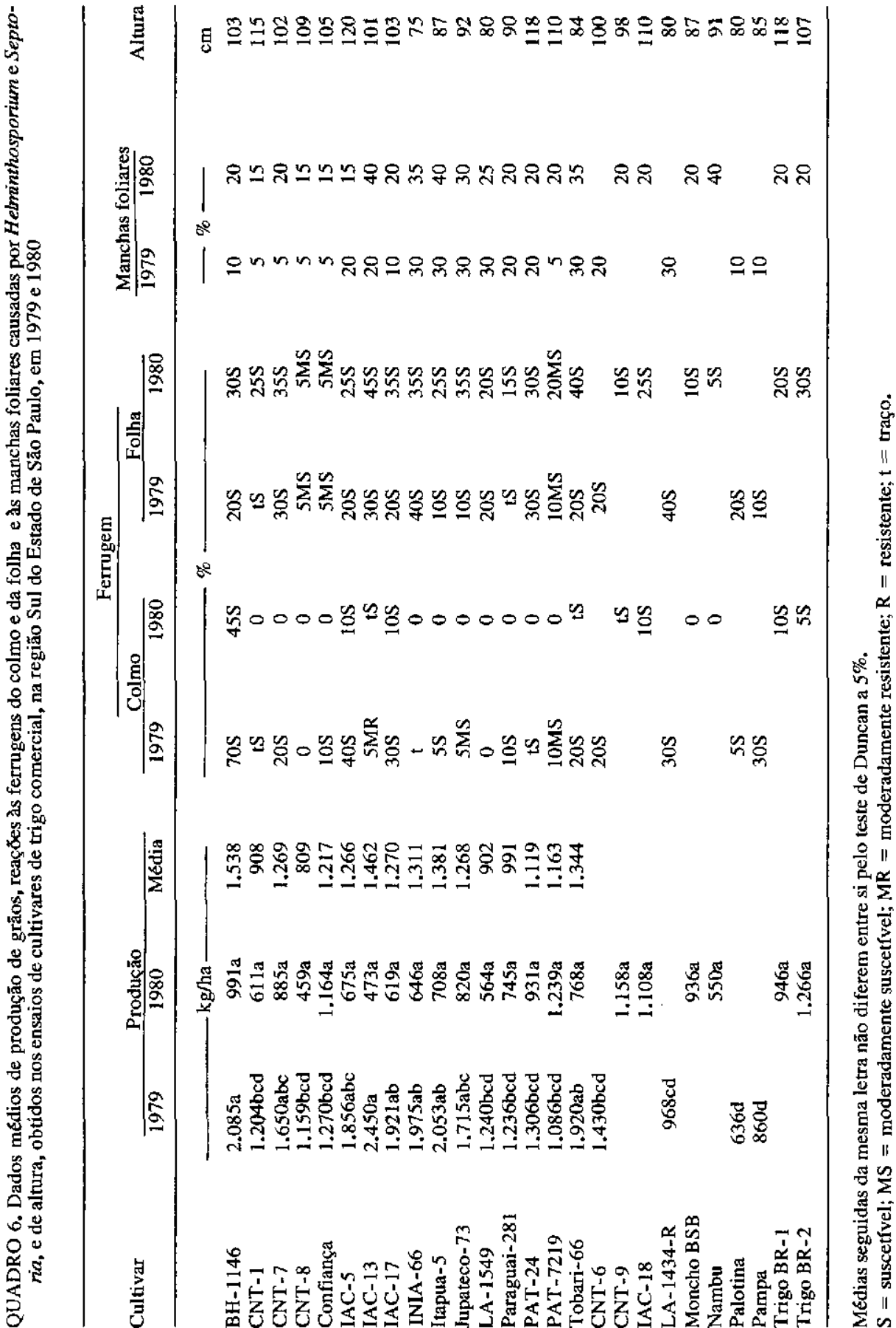


Das doenças na regiāo, a ferrugem-da-folha aparece com a maior incidência, vindo em segundo lugar as manchas foliares, enquanto a ferrugem-docolmo tem apresentado baixa incidência.

\section{CONCLUSÕES}

1. Os cultivares IAC-13, INIA-66, Itapua-5, PAT-24, IAC-17 e IAC-5 apresentaram melhor performance de produtividade de grăos, no Vale do Paranapanema.

2. Para a região Sul do Estado de São Paulo, destacaram-se os cultivares $\mathrm{BH}-1146$, IAC-13, Itapua-5, Tobari-66 e INIA-66.

3. Quanto à produtividade de grãos em solos com $\mathrm{Al}^{3+}$, sobressaíram os cultivares Trigo BR-4, IAC-21, IAC-18, Alondra-45 e 46, Trigo BR-5, PAT-72247, IAPAR-3, Charrua e CEP-7596.

4. Os cultivares PAT-24, IAC-13, INIA-66, CNT-8, Alondra, MR-74044 e MR-74501 mostraram maior resistência à ferrugem-do-colmo, em condiçōes de campo; já com relação à ferrugem-da-folha, destacaram-se o IAPAR-1, IAPAR-3, Alondra e CNT-8.

5. A alta incidência da ferrugem-do-colmo na regiāo Sul do Estado de Säo Paulo poderá inviabilizar futuramente a semeadura dos cultivares de trigo $\mathrm{BH}-1146$ e IAC-5 (Maringá), em razão da prevalência das atuais raças, às quais eles se têm mostrado altamente suscetiveis.

\section{SUMMARY}

\section{COMPARATIVE TRIALS OF WHEAT CULTIVARS IN SOUTHERN STATE OF SĀO PAULO, BRAZIL}

A study was made on the performance of wheat cultivars tolerant, non tolerant to aluminum toxicity and commercial cultivars in several regions of State of São Paulo, during the cropping season of 1979 and 1980. In the trials of cultivars for soils with $\mathrm{Al}^{3+}$ only the cultivars $\mathrm{IAC}-21$ and $\mathrm{BR}-4$ were superior to the control $\mathrm{BH}-1146$ in yield in the studied biennium. In the tests of cultivars for soils without $\mathrm{Al}^{3+}$, Tucano, Anahuac, SEMA 220, El Pato, Mitacoré, Aracatu, MR-74042 and MR-74501 were higher in yield than the control. In 1979/80, the cultivars IAC-13, INIA-66, Itapua-5, PAT-24, IAC-17, IAC-5, BH-1146 and Tobari-66 showed superior performance for yield. In a general way, the cultivars PAT-24, IAC-13, INIA-66, CNT-8, Alondra, MR-74044, MR-74501 and Sparrow "S" showed resistance to prevalent races of Puccinia graminis f. sp. tritici. Cultivars Mitacoré, Aracatu, Alondra and CNT-8 presented lower susceptibility to $P$. recondita under field conditions.

Index terms: Triticum aestivum L., production, aluminum toxicity, resistance, rust, Puccinia graminis f. sp. tritici, $P$. recondita. 


\section{REFERÊNCIAS BIBLIOGRÁFICAS}

BANCO DO BRASIL S.A. DIRUR-CTRIN. A comercializaçâo estatal, 1962-1979. Porto Alegre, $1979.111 \mathrm{p}$.

BAYMA, A.C. Trigo. Rio de Janeiro, Serviço de Informação Agrícola, 1960. 2v. (Estudos Técnicos, 14)

CAMPINAS. Instituto Agronômico. Tabelas de adubação e de calagem das principais culturas econômicas do Estado de São Paulo. Campinas, 1977. Item 78, p.189-191. (Boletim, 209)

COELHO, E.T. Ferrugem-do-colmo do trigo no Brasil: levantamento de raças em 1978 e 1979 e testes de resistência dos cultivares do Ensaio Norte Brasileiro. In: REUNIÃO DA COMISSÃO NORTE BRASILEIRA DE PESQUISA DE TRIGO, 6., CuritibaPR, 1980. p.13-19.

DUARTE, A.R. Tecnologia na agricultura. Consideraçöes sobre a produtividade do trigo brasileiro. São Paulo, USP, 1974. 144p. Tese. (Doutoramento)

FELf́CIO, J.C. Comportamento de cultivares de trigo em duas regiōes tritícolas do Estado de São Paulo. Campinas, Instituto Agronômico, 1980. 19p. (Boletim t€́cnico, 64)

GOMES, F.P. Curso de estatística experimental. Piracicaba, Escola Superior de Agricultura "Luiz de Queiroz", 1963. 384p.

INFORME DO CENTRO INTERNACIONAL DE MEJORAMIENTO DE MAIZ Y TRIGO. El Batán, México, CIMMYT, 1979. 62p.

MUZZILlI, O.; SANTOS, D.; PALHANO, J.B.; MANETTI FILHO, J.; LANIMANN, A.F.; GARCIA, A. \& CATANEO, A. Tolerância de cultivares de soja e trigo à acidez. do solo. Revista Brasileira de Ciência do Solo, Campinas, 2:34-40, 1978.

SCHRAM, W.; FULCO, W.S.; SOARES, M.H.G. \& ALMEIDA, A.M.P. Resistência de cultivares de trigo em experimentação ou cultivo no Rio Grande do Sul, às principais doenças fúngicas. Agronomia Sulriograndense, Porto Alegre, 10:31-39, 1974. 